\title{
Percepção de educadores sobre aspectos da educação ambiental em escolas do município de Ji-Paraná/RO
}

A Educação Ambiental (EA) deve ser tida como elemento estruturante da política ambiental, uma vez que abre um leque de perspectivas para a formação cidada e ética dos indivíduos. Por conta disso, deve-se buscar a introdução da EA, principalmente em âmbito escolar, sendo este um dos espaços primordiais à formação intelectual dos indivíduos. Nesse sentido, o objetivo do presente estudo foi realizar uma pesquisa exploratória, almejando conhecer o cenário da Educação Ambiental nas escolas do município de Ji-Paraná, Rondônia - Brasil, de forma que possíveis lacunas nessa temática possam dar ensejo à futuras iniciativas de fortalecer a EA no ensino básico. Para tanto, foram selecionadas 8 escolas estaduais para a aplicação de questionários, representando $20 \%$ do total de escolas estaduais no município. Conforme os resultados, $70 \%$ dos educadores participantes responderam que não são realizadas aulas de campo, ou atividades contínuas que abordem o tema de sustentabilidade ambiental na escola em que lecionam; 71,4\% dos professores afirmam não conhecer a Lei $9.795 / 99$, que dispõe sobre a Política Nacional de Educação Ambiental e somente 35,7\% se declaram preparados para desenvolver atividades de EA em sala de aula. Desta forma, os dados obtidos no estudo revelam que a Educação Ambiental ainda tem sido trabalhada de forma incipiente nas escolas estaduais do município de Ji-Paraná-RO. Po conseguinte, faz-se de extrema necessidade a inclusão, não somente de iniciativas isoladas, mas da EA como um todo no âmbito dos sistemas de ensino, de forma a proporcionar de forma efetiva a internalização dos aspectos ambientais no cotidiano social.

Palavras-chave: Lei 9795/99; Educação socioambiental; Sensibilização ambiental.

\section{Perception of educators on aspects of environmental education in schools in the municipality of Ji-Paraná/RO}

\begin{abstract}
Environmental Education (EA) created a structured element of environmental policy, since it opens up a range of perspectives for the formation of citizenship and ethics of individuals. Because of this, the introduction of AE should be sought, mainly in the school environment, being one of the primary spaces for the intellectual training of individuals. In this sense, the objective of the present study was to carry out an exploratory research, in addition to knowing the scenario of Environmental Education in schools in the municipality of Ji-Paraná, Rondônia - Brazil, so that possible gaps in this theme can be considered for the next initiatives of marketing a. EA in basic education. To this end, 8 state schools were selected to apply questionnaires, representing $20 \%$ of the total state schools in the municipality. According to the results, $70 \%$ of the participating educators respond that field classes or continuous activities that address the issue of environmental sustainability are not carried out in the school where they teach; $71.4 \%$ of teachers say they do not know Law 9,795/99, which discovered the National Environmental Education Policy and only $35.7 \%$ declared themselves prepared to develop EE activities in the classroom. Thus, the data obtained in the study reveal that Environmental Education was still incipiently developed in state schools in the municipality of Ji-Paraná-RO. For example, it is extremely necessary to include, not only strategic initiatives, but also EA as a set of educational systems, in order to allow an effective way to internalize environmental aspects in daily social life.
\end{abstract}

Keywords: Law 9795/99; Socio-environmental education; Environmental awareness.

Topic: Educação Ambiental

Reviewed anonymously in the process of blind peer.

Decauita Poliana Peixoto da Silva ii Universidade Federal de Rondônia, Brasil http://lattes.cnpq.br/6809292331117372 http://orcid.org/0000-0002-1667-0346 airam.azuos0000@gmail.com

Patrícia Soares de Maria de Medeiros (ii) Universidade Federal de Rondônia, Brasil http://lattes.cnpq.br/3519588719846194 http://orcid.org/0000-0001-6245-6108 patricia@unir.br

Núbia Déborah Araújo Caramello Universidade Federal de Rondônia, Brasil http://lattes.cnpq.br/8155132371455051 http://orcid.org/0000-0002-2167-9759 geocaramellofri@gmail.com
Received: 06/10/2020

Approved: $\mathbf{2 8 / 1 1 / 2 0 2 0}$
Referencing this:

SILVA, D. P. P.; MEDEIROS, P. S. M.; CARAMELLO, N. D. A.. Percepção de educadores sobre aspectos da educação ambiental em escolas do município de Ji-Paraná/RO. Revista Ibero Americana de Ciências Ambientais, v.11, n.6, p.688-699, 2020. DOI: http://doi.org/10.6008/CBPC2179-6858.2020.006.0055 


\section{INTRODUÇÃO}

Historicamente, a Educação Ambiental (EA) foi primariamente reconhecida na Conferência de Estocolmo como um elemento a ser utilizado no combate aos problemas ambientais (PICCOLI et al., 2017). A expansão dessa temática ocorreu a partir da década de 1970 com a realização de conferências próprias desse tema e a produção de materiais e documentos norteadores para que os governos apliquem em suas políticas públicas (BARCHI, 2016).

Um aspecto importante a ser levantado é que, a partir da diversidade de atores atuantes no campo social da Educação Ambiental, pode-se observar que esta não é um seguimento homogêneo. Dentre as principais vertentes da EA pode-se citar as vertentes Conservadorista, Pragmática e Crítica. Inicialmente, era predominante a concepção conservadorista, na qual primava-se pela sensibilização humana a partir da visão ecológica (LAYARGUES et al., 2014). Ao longo da década de 1990 também ascendeu a linha pedagógica ambiental pragmática, pautada na responsabilização individual e com a concepção de que a ciência e tecnologia vão resolver todos os problemas ambientais. Esta vertente conduz a mudanças pouco profundas na relação da sociedade com o ambiente pois não se preocupa em abordar as raízes do problema por meio das dinâmicas sociais (NOGUEIRA et al., 2017). Todavia, isoladamente, os atos normativos, avanços tecnológicos e políticas públicas não são suficientes para superar os desafios ambientais, necessitando da mudança comportamental do homem frente ao ambiente (BAYRAM, 2012; FRANTZ et al., 2014).

Nesse sentido, surge a Educação Ambiental Crítica, sendo um dos seus pilares o pensamento Freireano, bem como os princípios marxistas que indicavam a necessidade de compreender as relações socioculturais e históricas para lidar com a crise ambiental (HUME et al., 2015; LAYARGUES et al., 2014; RAYMUNDO et al., 2010). Conceitualmente, pode se caracterizar a EA em sua vertente crítica como "um processo educativo que empreende uma reflexão crítica sobre a realidade objetiva, configura-se numa proposta formativa que contribui para promover o desenvolvimento da consciência filosófica, demanda legítima e necessária ao processo educativo escolar" (MAIA et al., 2015).

Desta forma, a Educação Ambiental deve ser tida como elemento estruturante da política ambiental, uma vez que abre um leque de perspectivas para a formação cidadã e ética dos indivíduos (CONY, 2013; HUME et al., 2015). Ou seja, a EA é, em sua essência, um campo de interação política e não deve ser tida puramente como um instrumento de alteração do comportamento, mas um meio de ascensão social (HUME et al., 2015; NOGUEIRA et al., 2017).

O viés do "pensamento crítico" não separa a Educação da Educação Ambiental, uma vez que preconiza a adoção de um cenário pedagógico que tenha o ambiente como agente gerador do currículo. Ou seja, não é a Educação Ambiental um elemento a ser introduzido no processo de escolarização, mas sim uma das justificativas deste (NOGUEIRA et al., 2017).

Nesse ponto, destaca-se a importância de uma nova linguagem de ensino, que proponha cooperação e trabalho em equipe dos diversos educadores, para que o conteúdo, em geral, dialogue constantemente com o ambiente, bem como deixar de lado o reducionismo e a fragmentação do ensino (VALDERRAMA- 
HERNÁNDEZ et al., 2017), uma observação inserida na Agenda 21, porém que pouco expansão teve nas práticas escolares, tendo caso isolados de sua implantação no sistema de ensino.

Por conta disso, deve-se buscar a introdução da EA de forma transversal, principalmente em âmbito escolar, sendo este um dos espaços primordiais à formação intelectual dos indivíduos. Porém, além de fortalecer a inter e a transdisciplinaridade, a visão holística das questões ambientais, a conscientização crítica, o engajamento social; a EA deve ser introduzida como uma dimensão integrante no ensino em todas as suas modalidades e níveis já existentes, como estabelece a própria Política Nacional de Educação Ambiental (BRASIL, 1999), e não como um mero conteúdo adicional a ser tratado de forma separada do contexto da escolarização.

Considerando ainda que EA faz parte do próprio engraxamento social. Como manter a Pandemia que atinge o Brasil no ano de 2020 e o mundo fora do currículo? A Educação ambiental exige sensibilidade e empatia pelos acontecimentos no planeta atingindo âmbitos econômicos, culturais e ambientais. Se esses acontecimentos estão constantemente nas mídias e são ponto de atenção dos alunos. Da mesma forma ocorre com a enchente do rio Ji-Paraná que ocorre todo ano no município. São conteúdos vivos, em que muitos dos alunos estão inseridos e são impactados diretamente.

Neste viés a ideia de transformar a relação entre a sociedade e o ambiente por meio da escola é válida, visto que as instituições de ensino desempenham papel primordial na disseminação de valores relativos à sustentabilidade, levando o que é ensino para fora dos muros da escola (BASTOS et al., 2016). A escola é um componente muito presente na vida social, uma que vez que é constituída até mesmo nas localidades mais remotas e inacessíveis. Desta forma, além do inegável papel que exerce na formação da população, é preciso exaltar sua função influenciadora, principalmente nesse período em que se busca a valorização das instituições de ensino básico (MOREIRA et al., 2013).

Nesse sentido, Moreira et al. (2013) reforça a importância de que a escola adquira a capacidade de influenciar a comunidade local por meio de ações de gestão sustentável em seu próprio espaço físico e sugerem como medidas de gestão a tomada de decisão democrática e participativa para implementação de medidas de uso eficiente da água; adequação dos projetos políticos pedagógicos de forma a incentivar os educadores à compreensão mais aprofundada dos problemas ambientais e a abordagem do tema de forma interdisciplinar; interação com a comunidade e com os problemas locais, de forma a incentivar a cidadania ambiental e inserção da temática da saúde ambiental no ambiente escolar.

Sendo assim, a educação ambiental é um dos instrumentos que podem atingir diretamente a sensibilização do cidadão acerca da importância de transformações efetivas, tanto comportamentais quanto políticas, e da adoção de soluções baseadas nos processos naturais, a fim de garantir a manutenção de processos essenciais ligados à qualidade de vida e aos hábitos inerentes à vida contemporânea. Nesse sentido, o objetivo do presente estudo foi realizar uma pesquisa exploratória, almejando conhecer o cenário da Educação Ambiental nas escolas do município de Ji-Paraná, Rondônia. 


\section{MATERIAIS E MÉTODOS}

A pesquisa foi aplicada no município de Ji-Paraná, região central do Estado de Rondônia, inserida na geoeconômia amazônica, Região Norte do Brasil. Estima-se que o município possua aproximadamente 129.000 habitantes (IBGE, 2020). De acordo com a Secretaria Municipal de Educação de Ji-Paraná-RO (SEMED) o sistema de ensino municipal conta com 31 escolas, enquanto o sistema estadual de ensino possui 41 escolas no município, segundo a Coordenadoria Regional de Educação de Ji-Paraná.

De forma a alcançar docentes dos diversos níveis de ensino, foram selecionadas 8 escolas estaduais (Figura 1) para a aplicação dos questionários, representando $20 \%$ do total de escolas estaduais inseridas no município, uma vez que as escolas municipais são responsáveis prioritariamente pelo ensino infantil e fundamental, de $1^{\circ}$ a $5^{\circ}$ ano. As escolas selecionadas são todas localizadas na zona urbana, porém buscou-se espacializar os locais de estudo de forma a abranger escolas centrais e periféricas.
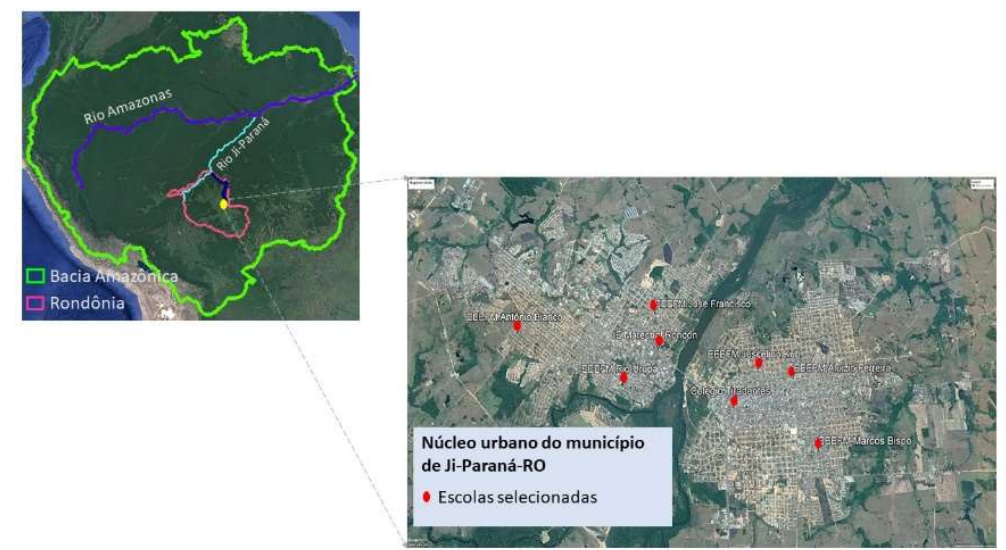

Figura 1: Localização das escolas integrantes da pesquisa, Ji-Paraná-RO. Fonte: Google Earth.

Os dados relativos ao contexto da Educação Ambiental (EA) em âmbito escolar foram obtidos a partir da aplicação de questionários. Esta é uma técnica de coleta de dados característica de pesquisas descritivas, sendo esta uma modalidade de pesquisa que visa registrar e descrever os dados, sem que haja interferência nos mesmos (PRODANOV et al., 2013). No entanto, o presente trabalho se aproxima, relativamente, da pesquisa exploratória, uma vez que o objetivo principal na aplicação dos questionários aos professores é conhecer o contexto da Educação Ambiental no ensino básico do município. Conforme Gil (2002) e Prodanov et al. (2013), a pesquisa exploratória tem como finalidade proporcionar familiaridade com o problema, oferecer maiores informações sobre o assunto e criar hipóteses.

O questionário aplicado continha 12 perguntas relacionadas a iniciativas de Educação Ambiental nas escolas, conforme adaptação da matriz de indicadores de EA proposta por Vieira et al. (2016). Os indicadores de educação ambiental utilizados para a obtenção da visão geral das atividades sobre essa temática que são desenvolvidas nas escolas selecionadas estão presentes na Tabela 1.

Tabela 1: Questões contidas no questionário de Educação Ambiental aplicado em escolas do município de Ji-ParanáRO, maio de 2019.

\begin{tabular}{ll}
\hline Q1 & A escola realiza atividades socioambientais nas datas elencadas abaixo? \\
Q2 & São realizadas aulas de campo para trabalhar as questões socioambientais locais e regionais? \\
Q3 & Na escola são realizados programas, atividades contínuas ou projetos de pesquisa voltados para a sustentabilidade do meio \\
\hline
\end{tabular}




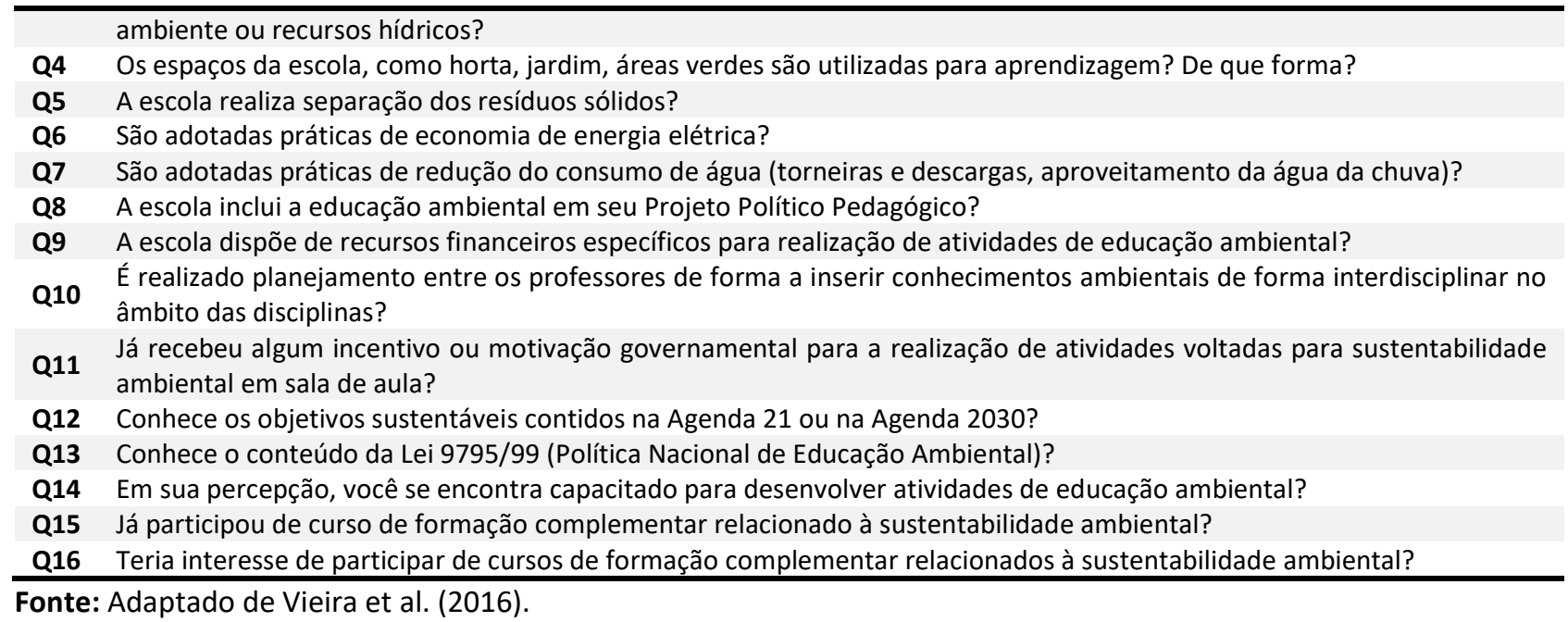

Ao todo foram aplicados 103 questionários físicos aos professores, com tempo para preenchimento de pelo menos uma semana. Posteriormente foi feito o retorno de, no mínimo, 2 vezes em cada escola para coleta dos questionários. Juntamente com os questionários, todos os participantes da pesquisa assinaram um termo de livre consentimento, o qual continha informações sobre os objetivos principais da pesquisa e os dados dos pesquisadores. Os resultados foram analisados a partir da disposição gráfica dos dados priorizando a percepção dos docentes frente às ações de Educação Ambiental que são realizadas nas escolas.

\section{RESULTADOS}

Dos 103 questionários distribuídos, 14 foram respondidos, o que representa 13,6\% do total. Tendo em vista as disposições da Política Nacional de Educação Ambiental de que a Educação Ambiental deve ser aplicada de forma universal em todos os níveis e áreas de ensino (BRASIL, 1999), os questionários foram aplicados aos professores de diversas disciplinas, sendo que, dos que contribuíram com a pesquisa, 35\% lecionam ciências humanas e sociais aplicadas, $14 \%$ ciências biológicas, $21 \%$ ciências exatas e $25 \%$ não mencionaram em que área lecionam.

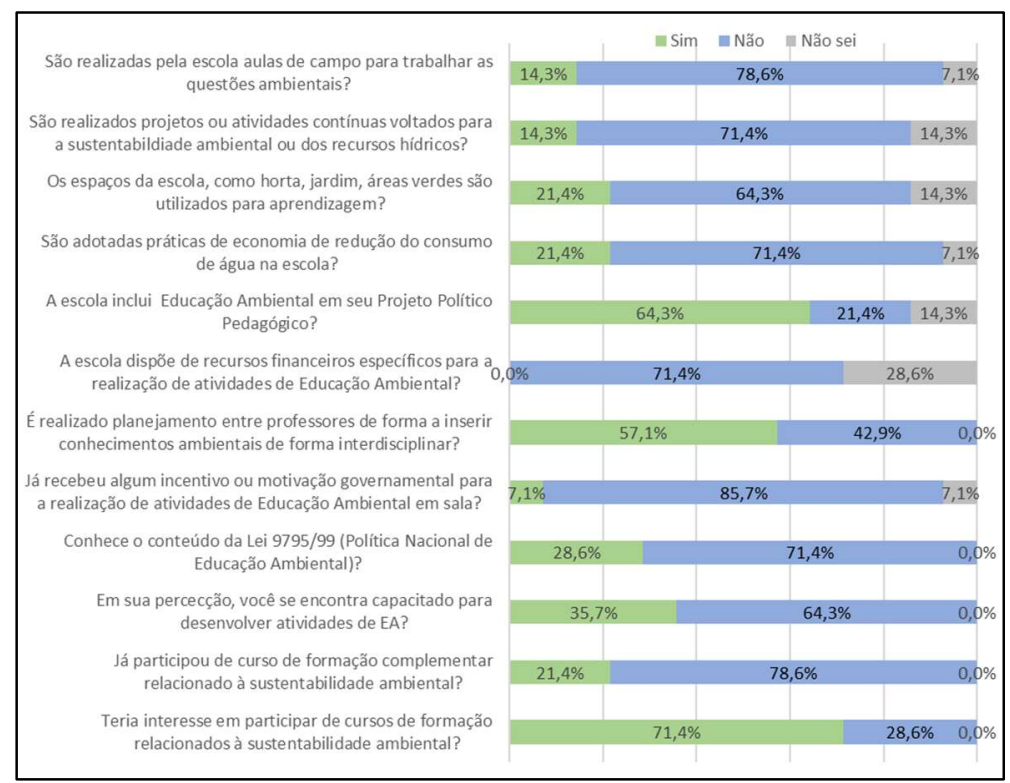

Figura 2: Percepções de educadores sobre a Educação Ambiental em escolas do município de Ji-Paraná-RO. 
A colaboração desses profissionais da educação na pesquisa oportunizou identificar um panorama da situação da implantação da Educação Ambiental como prática continua. Os resultados podem ser analisados na Figura 2.

Destaca-se que, apesar do tempo de pelo menos uma semana disponibilizado para o preenchimento do questionário, e de ter sido enfatizada a importância da pesquisa, muitos professores alegaram esquecimento ou indisponibilidade de tempo, devido à sobrecarga laboral com as atividades inerentes ao ensino escolar. Por conta disso, o índice de devolução foi relativamente baixo.

\section{DISCUSSÃO}

Apesar da EA ser predominantemente incluída ao ensino de ciências (Ensino Fundamental) e biologia (Ensino Médio) e Geografia (Ensino Fundamental e Médio), as demais disciplinas educacionais ensinadas nas escolas também têm importante função no desenvolvimento da aproximação do homem com o meio ambiente (MELO, 2007), afinal, a diretriz educacional vigente indica que a EA deve estar presente transversalmente e interdisciplinarmente em todos os níveis e espaços de ensino. Além do que, é estabelecido pela Política Nacional de Educação Ambiental (Lei 9.795/99) que a EA deve ser desenvolvida no âmbito do ensino formal e informal, de forma interdisciplinar em todas as modalidades de ensino (BRASIL, 1999).

Em relação aos dados obtidos, observa-se na Figura 02 que os professores, em sua maioria $(64,3 \%)$, indicaram que as escolas em que lecionam incluem a Educação Ambiental em seu Projeto Pedagógico. No entanto, de forma contrária, acima de $70 \%$ responderam que não são realizadas aulas de campo, ou atividades contínuas que abordem o tema de sustentabilidade ambiental.

Kato et al. (2016) conduziram um estudo com crianças da 4-5º́rie (Ensino Fundamental I), em que foram programadas palestras sobre diversos temas ambientais, como poluição do ar, da água e proteção ambiental conjuntamente ao conteúdo regular. Como resultados dos questionários aplicados, os autores obtiveram o aumento dos conhecimentos relacionados aos temas das palestras. Mesmo após meses, o conhecimento adquirido nas palestras ao longo do ano ainda permanecia mais elevados do que no início do estudo.

Nessa vertente, Bacci et al. (2008) enfatizam que atividades de educação ambiental que contextualizam a realidade local proporcionam maior compreensão e envolvimento de educadores e educandos, em contrapartida, atividades que possuem foco tão somente na sensibilização podem ser vistas com certa complexidade.

Conforme pesquisa realizada por Escrivão et al. (2014) no âmbito dos Programas de Educação Ambiental da USP e da UNESP, foi identificado que os programas não possuem efetividade no convencimento dos educandos quanto a necessidades de modificação de atitude próprias frente à questão ambiental. Em contrapartida, notou-se que o comprometimento com o tema é mais forte somente entre os membros internos do programa, como os professores e funcionários, que estão constantemente interagindo e trocando conhecimentos. 
O comportamento ambientalmente adequado é influenciado por vários fatores, dentre eles a motivação. Desta forma, entender a necessidade e o propósito do que está sendo ensinado é essencial para o sucesso do processo de aprendizagem (SRBINOVSKI et al., 2014). Conforme Melo (2007) e Simsekli (2015) a atenção e interesse dos estudantes é melhor captada a partir de atividades práticas que envolvem os problemas que eles próprios enfrentam cotidianamente.

Desta maneira, conforme mencionam Otto et al. (2017), o que falta para as abordagens em educação, no geral, não é em si o conteúdo, mas o componente motivacional. É preciso que os educandos tenham internamente a intenção de aprender. Por conta disso, Pérez-Rodrigues et al. (2017) complementam que é necessário estudar e melhorar o envolvimento dos educadores nas questões sustentáveis e incentivar o uso de métodos pedagógicos transformativos.

A conectividade ao ambiente é um pré-requisito para o engajamento em um comportamento mais ambientalmente adequado. Apesar dessa proposição, muitos projetos de educação ambiental têm como padrão promover o conteúdo ambiental, mas não fomentam a conectividade com o meio (OTTO et al., 2017).

O estudo desenvolvido por Frantz et al. (2014) demonstra que mesmo pequena exposição à conteúdos relacionados ao ecossistema, como por exemplo vídeos e observação local do espaço, tem o potencial de aumentar a conectividade ao ambiente externo. Desta forma, os autores concluem que educadores ambientais trabalhando ativamente nesta área, certamente, impactam o senso de conexão dos educandos com o ambiente.

Nessa mesma linha Simsekli (2015) desenvolveu uma pesquisa com crianças do ensino fundamental em que houve notável aumento no nível de percepção das crianças sobre os impactos ambientais nos recursos hídricos. A exemplo disso, antes da implementação de atividades relacionadas a essa temática somente $63 \%$ das crianças citaram a poluição do lago próximo como um problema ambiental da comunidade em que vivem, enquanto após as atividades $90 \%$ citaram esse fator.

A educação ambiental enriquece e promove o surgimento de novos significados na aprendizagem, de forma que ajuda os estudantes a interpretar o ambiente em que vivem para que possam atuar nele (LÓPEZ-ALCARRIA et al., 2014). Destaca-se também a importância das aulas de campo e atividades extraclasses, sendo estes os locais onde ocorrem as constatações do mundo real. É no campo que pode ser estimulada a capacidade de exploração e percepção do educando para a interpretação da natureza e para os impactos ambientais (BACCl et al., 2008).

Ferraro-Júnior (2013) indica o desenvolvimento da Educomunicação nas escolas, na qual os educadores produzam comunicação a partir da interpretação da comunidade e busquem mecanismos de envolvimento, sensibilização e interpretação para decodificar a Política Nacional de Recursos Hídricos de forma que seja adequadamente compreendida pela sociedade como um todo. Nesse sentido, Santos et al. (2017) sugerem a bacia hidrográfica como ponto de partida para envolver os educandos na realidade local e proporcionar uma visão integrada da interação entre os fatores antrópicos e ambientais da bacia. A bacia hidrográfica não só pode, como deve ser utilizada como área de desenvolvimento de práticas escolares, funcionando como campo integrador das diversas disciplinas (BACCl et al., 2008). 
Além disso, a Base Nacional Comum Curricular, abre $40 \%$ do currículo para ser inseridos as realidades onde os alunos estão inseridos (BRASIL, 2018), oportunizando que em distintas escalas de análise os acontecimentos que ocorrem dentro do estado de Rondônia e até mesmo na região Amazônica, possam alimentar os diálogos estabelecidos por distintas disciplinas e as múltiplas linguagens possíveis a serem exploradas no ambiente escolar. Buscando descontruir os muros da escola, para que o meio social em que ela integralmente faz parte seja naturalmente uma enciclopédia viva de experiências a serem exploradas.

No entanto, elenca-se uma série de causas que mitigam a implementação efetiva da EA nas escolas, tais como: tempo exíguo para introdução da temática no âmbito do conteúdo lecionado, currículo escolar sobrecarregado, déficit de recursos, insuficiência de capacitação dos educadores, a ausência de atitude e crença de alguns no ensino dessa temática e a carência de suporte por parte da estrutura administrativa das escolas (KATO et al., 2016; IACOB, 2013; VALDERRAMA-HERNÁNDEZ et al., 2017).

Infere-se que a escassez de projetos e atividades de aplicação a longo prazo nas escolas do município seja um reflexo, dentre outros aspectos, da escassez de incentivo e investimentos públicos para o desenvolvimento dessa vertente educacional no ensino formal. Além disso, $71 \%$ dos professores inclusos na pesquisa indicaram a ausência de recursos financeiros específicos para atividades de EA e $86 \%$ afirmaram nunca terem recebido qualquer incentivo ou motivação para a realização de atividades de EA em ambiente escolar.

Nesse sentido, destaca-se a importância dos gestores da escola para o fomento, planejamento, mobilização e motivação dos atores que compõe a escola de forma que estes possam estar engajados na realização de um ensino convergente aos princípios ambientais (BASTOS et al., 2016; SANTOS et al., 2017). No estudo desenvolvido por López-Alcarria et al. (2014), em que foram aplicados questionários sobre Educação Ambiental a 15 professores de ensino infantil, os autores concluíram que, em geral, a falta de interesse entre educadores em desenvolver projetos de EA se dá pela falta de incentivos entre as camadas hierárquicas mais estratégicas do sistema de ensino (coordenadores do sistema), bem como incentivos destes para com os professores.

Além disso, segundo dispõem Caciuc (2014) e Escrivão et al. (2014) a origem do problema que impede a Educação Ambiental de obter resultados mais significativos, no sentido de melhorar a relação homemambiente, é a falta de treinamento dos educadores para construir atitudes ambientalmente coerentes com seus alunos, uma vez que aqueles não são apropriadamente preparados para desenvolver essa visão em sala de aula. Em consonância a esse entendimento, 71,4\% dos professores afirmam não conhecer a Lei 9.795/99, que dispõe sobre a Política Nacional de Educação Ambiental, sendo que os $28,6 \%$ que afirmaram conhecer a lei são docentes de disciplinas referentes às ciências humanas e sociais aplicadas, como filosofia, português e sociologia.

Os educadores interessados nos processos educativos para sustentabilidade ambiental devem se sensibilizar e reconhecer as particularidades dos indivíduos presentes em determinado contexto. A partir do reconhecimento das potencialidades é que se fortalece cada indivíduo para se tornar sujeito ativo dos enfrentamentos cotidianos, comumente repletos de desigualdades (LUCA et al., 2012; HAMALOSMANOGLU, 
2012; PÉREZ-RODRIGUES et al., 2017).

Ainda conforme os dados desta pesquisa, $35,7 \%$ se declaram preparados para desenvolver atividades de EA em sala de aula, dentre estes, apenas um é docente das disciplinas relacionadas às ciências biológicas. Os resultados obtidos nessa questão vão ao encontro do estudo desenvolvido por López-Alcarria et al. (2014) em que, dos 15 professores que participaram da pesquisa, metade destes $(50 \%)$ reconhecem a importância de abordar tópicos relativos às questões ambientais na área educacional. No entanto, somente 13,3\% declararam ter alta experiência no ensino de EA, enquanto 40\% afirmam não possuir experiência alguma, ao passo que $46,7 \%$ informam ter alguma experiência.

Há um aumento no número de estudos relacionados à formação continuada de professores, porém, as questões metodológicas que justificam estes estudos não chegam a ser plenamente consideradas pelos educadores. Desta forma, as fontes de informação buscadas pelos professores para a inserção de Educação Ambiental na escola muitas vezes são insuficientes para provocar a reflexão sobre sua prática e conduzir à efetiva inserção (VALENTIN, 2014).

As práticas fragmentadas provêm do senso comum educacional, que parte da necessidade de ações mediante a realidade presente. Por conta disso, destaca-se a importância de incentivar os educadores ambientais, no sentido de estimulá-los a superar o senso comum educacional por meio da consciência crítica de sua prática, e conduzir os educandos à autonomia intelectual através da consciência filosófica, ou seja, a real compreensão da realidade (MAIA et al., 2015).

Os resultados do presente estudo revelaram a carência de formação complementar pelos educadores, uma vez que $78,6 \%$ indicaram nunca terem participado de curso de formação complementar sobre sustentabilidade ambiental. Porém, é importante destacar que $71,4 \%$ dos professores indicaram interesse em participar desse tipo de capacitação.

No trabalho desenvolvido por Santos et al. (2017), foi feito acompanhamento com professores de ensino fundamental no interior de São Paulo, durante todo o ano escolar de 2014. Buscou-se realizar reuniões periódicas com os professores de forma que os pesquisadores pudessem auxiliar no planejamento de atividades de Educação Ambiental em sala de aula. O objetivo era fomentar o desenvolvimento de atividades pelos professores, e não simplesmente apresentar propostas a serem realizadas por eles. Na conclusão do projeto, os professores enfatizaram a importância dos pesquisadores para a efetiva implementação das atividades. Desta forma, a universidade se destaca como um colaborador em potencial para projetos dessa natureza no sistema de ensino básico. Indica-se como possibilidade de colaboração entre órgãos/instituições ligadas à política ambiental e o sistema básico de ensino, a realização de oficinas, cursos de formação complementar, projetos de acompanhamento continuado nas escolas, dentre outros.

A Educação Ambiental traz o desafio de trabalhar em coletividade, de dialogar. O diálogo propicia a permuta de experiências e percepções diversas sobre o meio ambiente no qual todos estão inseridos, de forma que, ao se discutir a importância da existência do rio mais próximo da escola, por exemplo, pode-se explorar os usos múltiplos da água e como ela é importante de maneira diversa, dependendo do uso que dela se faz. Desta forma, o obstáculo a ser vencido para uma efetiva mudança nas relações entre o homem 
e o ambiente é agir conjuntamente, diferente da valorização do individual, que é tão presente em nossa sociedade (LUCA et al., 2012). A mobilização social tem como ponto de partida o território e todos os atores envolvidos, bem como as contribuições e conhecimentos por eles desenvolvidos (PICOLLI et al., 2017).

Como anteriormente mencionado, o índice de devolução dos questionários foi de apenas $13,6 \%$ do total entregue aos professores. Destaca-se que foi oferecido tempo de pelo menos uma semana para preenchimento do questionário, sendo que o recolhimento deste ocorreu pelo menos duas vezes em cada escola. De início, o objetivo era recolher os questionários na ocasião da entrega. No entanto, observou-se certa resistência por parte dos educadores no momento da visita. Alguns mencionaram falta de tempo, devido a correção de trabalhos e provas. Houve também aqueles que não quiseram responder ao questionário por achar que o tema ambiental não está relacionado à sua área de ensino. Além do mais, ao levarem o questionário para suas casas muitos alegaram ter esquecido de preenchê-lo. Todas essas questões podem também estar vinculadas a uma sobrecarga de atividades desenvolvidas por esses profissionais, que ministram de 32 a 35 aulas semanais, podendo atingir conforme a disciplina acima de 350 alunos por semana.

Todos os fatores supracitados contribuíram para os resultados insatisfatórios quanto ao volume de questionários respondidos. No entanto, estes são apenas fatores explícitos que revelam a desmotivação dos educadores em relação ao ensino no geral. Segundo Santos et al. (2017) a baixa motivação entre educadores é consequência de várias causas, dentro as quais: excesso de trabalho; baixa remuneração; indisciplina dos educandos; sobrecarga de conteúdo a ser dado; baixa flexibilidade da grade escolar para introdução de novos conteúdos e falta de preparação dos educadores. Desta forma, discorrem Maia et al. (2015):

Considerando a realidade objetiva da escola pública, percebemos que o professor é concebido como técnico e entendido como um realizador de tarefas, que deve ser treinado para resolver problemas relacionados à prática (...). Neste sentido, as propostas de formação de professores que se pautam nas políticas de formação vigentes, não se revelam adequadas para que eles pensem e reflitam de forma mais aprofundada sobre a prática, pois não fornecem elementos teórico-práticos consistentes para fundamentar suas ações.

A exemplo disso, no projeto desenvolvido por Santos et al. (2017), dos 39 professores, para os quais um projeto e EA foi proposto, somente 13 concordaram em participar e, dentre estes, somente 7 realmente desenvolveram as atividades, revelando a dificuldade da efetivação de um ensino voltado para os princípios ambientais devido às diversas incongruências existentes no ensino público no país.

Essa resistência, ainda pode ser atrelada a fatores como o não envolvimento na proposta, por desmotivação de desenvolvimento de desenvolvimento de projetos por falta de recursos como já mencionados. E até mesmo pela ausência de conhecimento de fatores motivadores a serem aplicados por meio de suas disciplinas.

Isto posto, depreende-se que a transformação da educação, para que seja condizente com os princípios ambientais, só ocorrerá efetivamente com a mudança de todo modelo de gestão, infraestrutura e cultura das instituições de ensino (BASTOS et al., 2016). Nesse sentido, ganha ainda mais destaque a necessidade de processos de formação continuada de educadores, de forma que compreendam a natureza interdisciplinar e globalizada da sustentabilidade para impulsionar essa transformação (PÉREZ-RODRIGUES et al., 2017). 


\section{CONCLUSÕES}

Os dados obtidos no estudo revelaram que a Educação Ambiental ainda tem sido trabalhada de forma incipiente nas escolas estaduais do município de Ji-Paraná-RO. Infere-se que está não seja uma realidade exclusiva do local de estudo. Por conseguinte, faz-se de extrema necessidade a inclusão, não somente de iniciativas isoladas, mas da EA como um todo no âmbito dos sistemas de ensino, de forma a proporcionar efetivamente a internalização dos aspectos ambientais no cotidiano social.

Conforme os dados da pesquisa, citam-se como fatores desafiadores para a efetividade da EA em nível escolar, a defasagem na implementação de políticas públicas já formuladas e, sobretudo, à sobrecarga curricular dos diversos educadores atuantes nas escolas. Juntamente a isso, tem-se a escassez de incentivos por parte dos gestores do sistema educacional para implementação da EA no âmbito das diversas disciplinas escolares e a deficiência na formação de educadores ambientais conscientes da importância da sua prática pedagógica, que possam auxiliar na formação de cidadãos críticos da realidade ambiental a sua volta.

AGRADECIMENTOS: As autoras agradecem ao Programa de Mestrado Profissional em Rede Nacional em Gestão e Regulação dos Recursos Hídricos - Prof. Água, projeto CAPES/ANA AUXPE n² 271/2015.

\section{REFERÊNCIAS}

BACCI, D. C.; PATACA, E. M.. Educação para a água. Estudos Avançados, São Paulo, v.22, n.63, 2008. DOI: https://doi.org/10.1590/S0103-40142008000200014

BARCHI, R.. Educação ambiental e (eco)governamentalidade. Ciência e Educação, Bauru, v.22, n.3, p.635-650, 2016. DOI: http://dx.doi.org/10.1590/1516-731320160030006

BASTOS, D. B. D.; RABINOVICI, A.. A importância do processo de formação de educadores ambientais na efetividade do Programa Nacional de Escolas Sustentáveis. Revbea, São Paulo, v.11, n.4, p.42-59, 2016.

BAYRAM, S. A.. On the role of intrinsic value in terms of environmental education. Procedia: Social and Behavioral Sciences, v.47, p.1087-1091, 2012. DOI: https://doi.org/10.1016/i.sbspro.2012.06.783

BRASIL. Ministério da Educação. Base Nacional Comum Curricular. Brasília: MEC, 2018.

BRASIL. Lei 9.795, de 27 de abril de 1999. Dispõe sobre a educação ambiental, institui a Política Nacional de Educação Ambiental. Brasília: DOU, 1999.

CACIUC, V. T.. Ecocentric reflections on the realization of environmental education. Procedia: Social and Behavioral Sciences, v.137, p.93-99, 2014. DOI: https://doi.org/10.1016/j.sbspro.2014.05.258

CONY, S.. Da Bahia ao Rio Grande do Sul, de Salvador a Bento Gonçalves: O Encontro das Águas. In: PAULA JÚNIOR, F.; MODAELLI, S.. Política de águas e educação ambiental: processos dialógicos e formativos em planejamento e gestão de recursos hídricos. Brasília: MMA, 2013. p.288.
ESCRIVÃO, G.; NAGANO, M.. Gestão do conhecimento na Educação Ambiental: estudo de casos em programas de educação ambiental em universidades brasileiras. Perspectivas em Ciência da Informação, Belo Horizonte, v.19, n.4, p.136-159, 2014. DOI: https://doi.org/10.1590/1981-5344/1602

FERRARO JÚNIOR, L. A.. Desafios dos caminhos ambientalistas: um mapa imaginário para transformações democráticas. In: PAULA-JÚNIOR, F.; MODAELLI, S.. Política de águas e educação ambiental: processos dialógicos e formativos em planejamento e gestão de recursos hídricos. Brasília: MMA/SRHU, 2013. p.288.

FRANTZ, C. M.; MAYER, F. S.. The importance of connection to nature in assessing environmental education programs. Studies in Educational Evaluation, v.41, p.85-89, 2014. DOI: https://doi.org/10.1016/j.stueduc.2013.10.001

GIL, A. C.. Como elaborar projetos de pesquisa. 4 ed. São Paulo: Atlas, 2002.

HAMALOSMANOGLU, M.. The place of environmental education in science education curricula in Turkey. Procedia - Social and Behavioral Sciences, v.46, p.4839-4844, 2012. DOI: https://doi.org/10.1016/j.sbspro.2012.06.345

HUME, T.; BARRY, J.. Environmental Education and Education for Sustainable Development. 2 ed. International Encyclopedia of the Social \& Behavioral Sciences, 2015.

IACOB, M.. Environmental Education: Policy and Practice. Reggae- Revista de Gestão e Avaliação Educacional, Santa Maria, v.2, n.4, p.63-71, 2013.

IBGE. Instituto Brasileiro de Geografia e Estatística. Cidades. 
Rio de Janeiro: IBGE, 2020.

KATO, T.; HOANG, T. T. P.. Measuring the effect of environmental education for sustainable development at elementary schools: A case study in Da Nang city, Vietnam. Sustainable Environment Research, v.26, p.274-286, 2016. DOI: https://doi.org/10.1016/j.serj.2016.08.005

LAYRARGUES, P. P.; LIMA, G. F. C.. As macrotendências político-pedagógicas da Educação Ambiental brasileira. Ambiente e Sociedade, v.17, n.1, p.23-40, 2014.

LÓPEZ-ALCARRIA, A.; GUTIÉRREZ-PÉREZ, J.; POZA-VILCHES, F.. Preschool Education Professionals as Mediators of Environmental Health Education. Procedia - Social and Behavioral Sciences, v.132, p.639-646, 2014. DOI: https://doi.org/10.1016/j.sbspro.2014.04.366

LUCA, A. Q.; ANDRADE, D. F.; SORRENTINO, M.. O diálogo como objeto de pesquisa na Educação Ambiental. Educ. Real., Porto Alegre, v.37, n.2, p.589-606, 2012. DOI: https://doi.org/10.1590/S2175-62362012000200014

MAIA, J. S. S.; TEIXEIRA, L. A.. Formação de professores e Educação Ambiental na escola pública: contribuições da pedagogia histórico-crítica. HISTEDBR, Campinas, n.63, p.293-305, 2015. DOI: https://doi.org/10.20396/rho.v15i63.8641185

MELO, G. P.. Educação ambiental para professores e outros agentes multiplicadores. João Pessoa: Superintendência do IBAMA na Paraíba, 2007.

MOREIRA, T.; BARSOSA, N. H. R.; SANTOS, R. S.; COSTA, L. C. L.. Educação Ambiental e Gestão das Águas no ensino formal. In: PAULA-JÚNIOR, F.; MODAELLI, S.. Política de águas e educação ambiental: processos dialógicos e formativos em planejamento e gestão de recursos hídricos. Brasília: MMA, 2013. p.288.

NOGUEIRA, L. S. B.; TEIXEIRA, C.. Os entraves da tendência pragmática para uma Educação Ambiental emancipatória. Cadernos CIMEAC, v.7, n.2, p.146-161, 2017. DOI: https://doi.org/10.18554/cimeac.v7i2.2024

OTTO, S.; PENSINI, P.. Nature-based environmental education of children: Environmental knowledge and connectedness to nature, together, are related to ecological behavior. Global Environmental Change, v.47, p.88-94, 2017. DOI: https://doi.org/10.1016/i.gloenvcha.2017.09.009

PÉREZ-RODRÍGUEZ, U.; VALERA-LOSADA, M.; ÁLVARZ-LIRES, F. J.; VEGA-MARCOTE, P.. Attitudes of preservice teachers: Design and validation of an attitude scale toward environmental education. Journal of Cleaner Production,

v.164, p.634-641, 2017. DOI:

https://doi.org/10.1016/j.jclepro.2017.06.245

PICCOLI, A. S.; KLIGERMAN, D. C.; COHEN, S. C.. Políticas em saúde, saneamento e educação: trajetória da participação social na saúde coletiva. Saúde Soc., São Paulo, v.26, n.2, p.397-410, 2017. DOI: https://doi.org/10.1590/s010412902017160043

PRODANOV, C. C.; FREITAS, E. C.. Metodologia do trabalho científico: métodos e técnicos da pesquisa e do trabalho acadêmico. 2 ed. Nova Hamburgo: Feevale, 2013.

RAYMUNDO, L. S.; KUHNEN, A.. A Psicologia e a Educação Ambiental. Revista de Ciências Humanas, Florianópolis, v.44, n.2, p.435-450, 2010.

DOI: https://doi.org/10.5007/2178-4582.2010v44n2p435

SANTOS, C. R.; GRILLI, N. M.; GHILARDI-LOPES, N. P.. A collaborative work process for the development of coastal environmental education activities in a public school in São Sebastião (São Paulo State, Brazil). Ocean \& Coastal Management, v.164, p.147-155, 2017. DOI: https://doi.org/10.1016/j.ocecoaman.2017.08.011

SIMSEKLI, Y.. An Implementation to Raise Environmental Awareness of Elementary Education Students. Procedia: Social and Behavioral Sciences, v.191, p.222-226, 2015. DOI: https://doi.org/10.1016/i.sbspro.2015.04.449

SRBINOVSKI, M.; ISMAILI, M.; ZENKI, V.. Didactic Preconditions for Environmental Education in the Macedonian Secondary School. Procedia - Social and Behavioral Sciences, v.116, p.88-94, 2014. DOI: https://doi.org/10.1016/j.sbspro.2014.01.173

VALDERRAMA-HERNÁNDEZ, R.; ALCÁNTARA, L.; LIMÓN, D.. The complexity of environmental education: teaching ideas and strategies from teachers. Procedia - Social and Behavioral Sciences, v.237, p.968-974, 2017. DOI: https://doi.org/10.1016/i.sbspro.2017.02.137

VALENTIN, L.. A dimensão política na formação continuada de professores em educação ambiental. Rev. Eletrônica Mestr. Educ. Ambiental, v.31, n.2, p.58-72, 2014. DOI: http://doi.org/10.14295/remea.v31i2.4630

VIEIRA, S. R.; CAMPOS, M. A. T.; MORAIS, J. L.. Proposta de matriz de indicadores de educação ambiental para avaliação da sustentabilidade socioambiental na escola. Rev.

Eletrônica do Mestrado em Educação Ambiental, v.33, n.2, p.106-123, 2016. DOI: https://doi.org/10.14295/remea.v33i2.5633

A CBPC - Companhia Brasileira de Produção Científica (CNPJ: 11.221.422/0001-03) detém os direitos materiais desta publicação. Os direitos referem-se à publicação do trabalho em qualquer parte do mundo, incluindo os direitos às renovações, expansões e disseminações da contribuição, bem como outros direitos subsidiários. Todos os trabalhos publicados eletronicamente poderão posteriormente ser publicados em coletâneas impressas sob coordenação da Sustenere Publishing, da Companhia Brasileira de Produção Científica e seus parceiros autorizados. Os (as) autores (as) preservam os direitos autorais, mas não têm permissão para a publicação da contribuição em outro meio, impresso ou digital, em português ou em tradução. 